FARIA, C.M.B.; COSTA, N.D.; FARIA, A.F. Ação de calcário e gesso sobre características químicas do solo e na produtividade e qualidade do tomate e melão. Horticultura Brasileira, Brasília, v. 21, n. 4, p.615-619, outubro/dezembro 2003.

\title{
Ação de calcário e gesso sobre características químicas do solo e na pro- dutividade e qualidade do tomate e melão
}

\author{
Clementino M.B. Faria ${ }^{1}$; Nivaldo D. Costa ${ }^{1}$; Arquimedes F. Faria ${ }^{2}$ \\ ${ }^{1}$ Embrapa Semi-Árido, C. Postal 23, 56370-970 Petrolina-PE; E-mail: clementi@cpatsa.embrapa.br; ${ }^{2}$ Eng. Agr., Estagiário da Embrapa \\ Semi-Árido
}

\section{RESUMO}

Realizou-se dois experimentos repetidos no mesmo local, em Argissolo Vermelho-Amarelo, de textura arenosa, do Submédio São Francisco, para avaliar a influência da calagem e da gessagem nas características do solo e na produtividade e qualidade dos frutos do tomateiro e meloeiro. O delineamento foi de blocos ao acaso, com quatro repetições e sete tratamentos [testemunha; 0,5 da necessidade de calagem (N.C.) com $100 \%$ de calcário (Cal.); 1xN.C. com Cal.; 2xN.C. com Cal.; 0,5xN.C. com $2 / 3$ de calcário e $1 / 3$ de gesso (Cal.Ges.); 1,0xN.C. com Cal.Ges. e 2,0xN.C. com Cal.Ges]. O calcário e gesso foram aplicados em novembro de 2000; o cultivo do tomate foi conduzido de maio a agosto e o do melão, de setembro a novembro de 2001. A calagem e a gessagem promoveram incre-

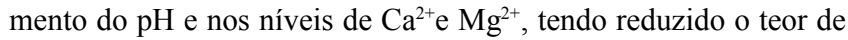
$\mathrm{Al}^{3+}$ do solo, com efeito mais pronunciado no aumento dos teores do $\mathrm{Ca}^{2+}$ em até $60 \%$ e na redução do $\mathrm{Al}^{3+}$ em até $68,7 \%$. O calcário isolado foi mais eficiente para neutralização do $\mathrm{Al}^{3+} \mathrm{em}$ maiores profundidades, tendo resultado em maiores produtividades de melão, em comparação com os tratamentos em que o calcário foi associado ao gesso. Com o uso de 2,0 $\mathrm{tha}^{-1}$ de calcário, equivalente a $1 \mathrm{xN}$.C, foi suficiente para se obter uma produtividade de $22,5 \mathrm{t} \mathrm{ha}^{-1}$ de melão, significativamente superior à da testemunha $\left(16,8 \mathrm{tha}^{-1}\right)$ e reduzir em $80,4 \%$ a ocorrência da podridão apical do tomate. Portanto, a gessagem não se mostrou necessária para essas culturas.

Palavras-chave: Lycopersicon esculentum, Cucumis melo, calagem, acidez, podridão apical.

\begin{abstract}
Lime and gypsum effects on soil chemical characteristics and on yield and quality of tomato and melon

The influence of lime and gypsum on soil characteristics and on yield and quality of tomato and melon fruits was evaluated in two experiments, carried out in the same site in a sandy Red Yellow Argisol in the Submedio São Francisco River region. The experimental design was a randomized complete block with four replications and seven treatments: 1) control; 2) half of liming need (N.C.) as limestone (Cal.); 3) 1 x N.C. (Cal.); 4) 2 x N.C. (Cal.); 5) $0.5 \times$ N.C. as $2 / 3$ limestone and $1 / 3$ gypsum (Cal.Ges.); 6) $1 \times$ N.C. (Cal.Ges.); 7) 2 x N.C. (Cal.Ges.). Limestone and gypsum were applied in November 2000; the tomato crop was grown from May to August 2001 and the melon crop from September to November 2001. Liming and gypsum applications resulted in an improvement of $\mathrm{pH}$ and increased the levels of $\mathrm{Ca}^{2+}$ and $\mathrm{Mg}^{2+}$ and reduced the amount of $\mathrm{Al}^{3+}$ in the soil, the effect being more evident on the increase of $\mathrm{Ca}^{2+}$ levels, up to $60 \%$, and on the decrease of $\mathrm{Al}^{3+}$ levels, up to $68.7 \%$. Limestone by itself was more efficient for neutralizing $\mathrm{Al}^{1+}$ at depth for melon crop than limestone associated with gypsum. The rate of 2.0 tons of limestone/ha ( 1 x N.C.) was enough to give a melon yield of 22.5 tons ha ${ }^{-1}$ and to reduce by $80.4 \%$ the incidence of the blossom end rot disease in tomatoes. Therefore, gypsum was not necessary for these crops.
\end{abstract}

Keywords: Lycopersicon esculentum, Cucumis melo, liming, acidity; blossom end rot disease.

(Recebido para publicação em 26 de maio de 2002 e aceito em 04 de julho de 2003)

$\mathrm{G}^{\mathrm{s}}$ rande parte dos solos do Vale do Submédio São Francisco apresenta textura arenosa, $\mathrm{pH}$ levemente ácido e teores de $\mathrm{Mg}$ e $\mathrm{K}$ trocáveis de baixo a médio, com baixa concentração de $\mathrm{Ca}$ trocável, o que limita a produtividade e a qualidade de frutos das culturas mais exigentes neste nutriente, como o tomate e o melão. Por essa razão, a calagem é mais recomendada para suprir o solo com cálcio e magnésio do que corrigir sua acidez. Nessas condições, o gesso agrícola poderia ser indicado também, para corrigir as deficiências de cálcio.

O gesso agrícola é um adubo que adiciona cálcio e enxofre ao solo, podendo transportar nutrientes catiônicos para camadas subsuperficiais e reduzir a atividade do alumínio tóxico. Por ou- tro lado, se essa lixiviação for intensa, pode arrastar as bases trocáveis para camadas mais profundas além da zona de crescimento radicular. Entre vários métodos que podem ser usados para o cálculo da quantidade de gesso a ser aplicada (Raij, 1988; Souza et al., 1996), um deles preconiza o seu uso junto com o calcário na proporção de 1/3 a 1/4 da dose desse corretivo (Alcarde, 1988). Resultados de pesquisa têm evidenciado a eficiência do gesso em aumentar os teores de cálcio, elevar os valores do $\mathrm{pH}$ e reduzir o alumínio tóxico no perfil do solo (Quaggio et al., 1993; Caires et al., 1999; Caires et al., 2001). Alguns trabalhos revelaram que a calagem também pode beneficiar as camadas profundas do solo (Quaggio et al., 1993;Caires et al., 1999). Summer et al. (1986) verificaram que o gesso aplicado na superfície foi menos eficiente para aumentar a disponibilidade do Ca trocável e reduzir a toxidez do Al no perfil do solo, do que o calcário aplicado em camadas profundas.

Martins et al.(1998) verificaram que apenas um entre sete experimentos apresentou influência positiva da substituição parcial do calcário pelo gesso na produção de soja, sendo $46,7 \%$, a substituição considerada ideal. Lima et al. (1984) verificaram que a produtividade máxima e a incidência mínima da podridão apical do tomate cultivado em solo de cerrado ocorreram com a aplicação de calcário com uma relação 2,5 de Ca para 1,0 de Mg, na dose 2 vezes a 
necessidade de calagem. Mayfield et al. (2001) constataram que os diferentes tipos de calcário proporcionaram $\mathrm{pH}$ do solo mais alto e um maior rendimento de frutos de tomate, quando comparados com a testemunha e com o uso de gesso.

Em solução nutritiva, Paiva et al. (1998) verificaram maior acúmulo de cálcio nos frutos, em condições de baixa umidade relativa (40\%). No entanto, a perda excessiva de água dos tecidos da planta conduziu a grande ocorrência de podridão apical quando o suprimento de cálcio foi baixo. Lester \& Grusak (1991) demonstraram o efeito positivo que o cálcio exerce sobre a cor da casca e na redução da incidência de doenças dos frutos de melão armazenados por um período de 22 dias após a colheita.

Avaliou-se nesse trabalho o efeito do calcário e do gesso sobre as características químicas do solo e sobre a produtividade e qualidade dos frutos de tomate e melão no Vale do Submédio São Francisco.

\section{MATERIAL E MÉTODOS}

O experimento foi conduzido na Embrapa Semi-Árido, em Petrolina, em Argissolo Vermelho-Amarelo de textura arenosa que apresentava, na camada arável $(0-20 \mathrm{~cm})$ as características químicas: $\mathrm{pH}$ em $\mathrm{H}_{2} \mathrm{O}=5,9$; C.E. $=0,4 \mathrm{dS}$ $\mathrm{m}^{-1} ; \mathrm{P}=15 \mathrm{mg} \mathrm{dm}^{-3} ; \mathrm{K}^{+}=0,30 \mathrm{cmol}_{\mathrm{c}}$ $\mathrm{dm}^{-3} ; \mathrm{Ca}^{2+}=0,90 \mathrm{cmol}_{\mathrm{c}} \mathrm{dm}^{-3} ; \mathrm{Mg}^{2+}=$ $0,40 \mathrm{cmol} \mathrm{dm}^{-3} \mathrm{e} \mathrm{Al}^{3+}=0,05 \mathrm{cmol} \mathrm{dm}^{-3}$. A necessidade de calagem (N.C.) desse solo foi de $1,8 \mathrm{t} \mathrm{ha}^{-1}$ de calcário, segundo o método: N.C. $\left(\mathrm{t} \mathrm{ha}{ }^{-1}\right)=3-$ $\left.\left[\mathrm{Ca}^{2+}+\mathrm{Mg}^{2+}\right)\right]+2 . \mathrm{Al}^{3+}$, recomendado para as culturas irrigadas no Submédio São Francisco, exigentes em cálcio (Cavalcanti, 1998).

O delineamento experimental foi blocos ao acaso com quatro repetições e os tratamentos: 1) testemunha (sem corretivo); 2) 0,5 x N.C. com $100 \%$ de calcário (Cal.); 3) 1 x N.C. com Cal.; 4) 2 x N.C. com Cal.; 5) 0,5 x N.C. com $2 /$ 3 de calcário e 1/3 de gesso (Cal.Ges.); 6) 1,0 x N.C. com Cal.Ges.; e 7) 2,0 x N.C. com Cal.Ges. O calcário utilizado apresentou um PRNT de 90\%, com 29\% de $\mathrm{CaO}$ e $19 \%$ de $\mathrm{MgO}$, fazendo com que a dose de calcário aplicada ficasse em 2,0 t ha ${ }^{-1}$. O gesso continha $16 \%$ de
$\mathrm{CaO}$. Os corretivos foram aplicados a lanço e incorporados ao solo por meio de enxada manual a uma profundidade de $12 \mathrm{~cm}$, em novembro de 2000 .

O tomate (Lycopersicon esculentum L.), cv. IPA 6 foi transplantado no campo, em maio, por meio do transplantio de mudas no espaçamento de 1,20 x 0,50 $\mathrm{m}$, com uma planta por cova e colhido em agosto/01. O melão (Cucumis melo L.), cv. AF 682 foi plantado no espaçamento de $1,80 \times 0,5 \mathrm{~m}$, com uma planta por cova, em setembro e colhido em novembro/01. Cada parcela tinha uma área de $57,6 \mathrm{~m}^{2}$. As duas culturas foram irrigadas por gotejamento, cuja lâmina d'água era determinada pelo coeficiente $\mathrm{kc}$ e a evaporação do tanque classe A.

Para o tomate, foi feita uma adubação uniforme de 135; 90 e $90 \mathrm{~kg} \mathrm{ha}^{-1} \mathrm{de}$ $\mathrm{N}, \mathrm{P}_{2} \mathrm{O}_{5}$ e $\mathrm{K}_{2} \mathrm{O}$, respectivamente, e para o melão, a adubação constou de 90; 80 e $80 \mathrm{~kg} \mathrm{ha}^{-1}$ de $\mathrm{N}, \mathrm{P}_{2} \mathrm{O}_{5}$ e $\mathrm{K}_{2} \mathrm{O}$, respectivamente, sob as formas de uréia, superfosfato simples e cloreto de potássio. Todo o fósforo, um terço do nitrogênio e metade do potássio foram aplicados em sulco antes do plantio das respectivas culturas. Os outros $2 / 3$ do nitrogênio e a outra metade do potássio foram aplicados via água de irrigação (fertirrigação). No tomate, a aplicação de N por fertirrigação foi feita no período de 20 a 55 dias após o plantio (DAP), e a de $\mathrm{K}$ no período de 40 a 60 DAP. No melão, essas adubações foram realizadas no período de 15 a 45 DAP para $\mathrm{Ne}$ 35 a 50 DAP para K.

Após a colheita do tomate, foram realizadas duas amostragens de solo nas entrelinhas de cada parcela, uma na profundidade de $0-20 \mathrm{~cm}$ e a outra de 20$40 \mathrm{~cm}$, constituídas de 10 amostras simples para uma amostra composta, nas quais foram determinados o $\mathrm{pH}$ e o Ca, $\mathrm{Mg}, \mathrm{K}$ e Al trocáveis e a granulometria em algumas delas, segundo Embrapa (1997). Avaliou-se a recuperação de cálcio no solo, oriundo do calcário ( $\mathrm{RCa}$ ) pela análise química nos tratamentos 2 , 3 e 4, através da fórmula: $\mathrm{RCa}(\%)=$ (CaTr - CaT)100/QCa, em que

$\mathrm{CaTr}=\mathrm{Ca}^{2+}$ do solo encontrado no tratamento com calcário,

$\mathrm{CaT}=\mathrm{Ca}^{2+}$ do solo encontrado na testemunha e
QCa $=$ Quantidade de Ca aplicado no solo pelo calcário, segundo Fole \& Grimm (1973).

Os dados de colheita das duas culturas foram submetidos às análises de variância e de regressão a 5\% de probabilidade (Snedecor \& Cochran, 1971) através de programa de computação (SAS, 1999). Para os dados relativos à porcentagem de ocorrência da podridão apical no tomate, usou-se a transformação arc.sen $\sqrt{ } \mathrm{x}$ antes de proceder essas análises.

\section{RESULTADOS E DISCUSSÃO}

\section{Efeito no solo}

Na Tabela 1 podem-se observar as alterações nas características do solo provocadas pela adição de calcário e gesso. Os maiores incrementos do $\mathrm{pH}$ foram de apenas 14,5 e 15,1\%, ocorridos nas profundidades de $0-20 \mathrm{~cm}$ e 20 $40 \mathrm{~cm}$, respectivamente, com o emprego da maior dose de calcário, $4.000 \mathrm{~kg}$ ha $^{-1}\left(2 \times\right.$ N.C.). Para $\mathrm{Ca}^{2+}$ trocável, os incrementos foram mais acentuados, variando de 10 a $60 \%$ e 0 a $50 \%$ nas profundidades de $0-20 \mathrm{~cm}$ e $20-40 \mathrm{~cm}$, conforme a dose da calagem, com índices ligeiramente superiores para a associação calcário e gesso. Com a dose de 1 x N.C., na forma de calcário ou com a metade da N.C., na forma de calcário e gesso os teores de $\mathrm{Ca}^{2+}$ foram elevados para níveis entre 1,21-2,40 $\mathrm{cmol}_{c} \mathrm{dm}^{-3}$, considerados médios (Ribeiro et al., 1999). Estes resultados eram previstos por se tratar de um solo arenoso, de baixa CTC, com baixa acidez e baixos teores de $\mathrm{Al}$ tóxico, mas pobre em $\mathrm{Ca}$ trocável.

Quanto ao $\mathrm{Mg}^{2+}$ trocável do solo, observa-se que os teores já se encontravam na faixa de nível médio $(0,46-0,90$ cmol $\mathrm{dm}^{-3}$ ), segundo Ribeiro et al. (1999), e com a dose mais elevada dos corretivos, os teores atingiram níveis altos. Com a dose 2 x N.C., nas formas de calcário e de calcário e gesso, obtiveram-se incrementos de 57,1 e 42,8\% na profundidade de $0-20 \mathrm{~cm}$, respectivamente. $\mathrm{Na}$ camada mais profunda, verificou-se apenas um incremento de $11,1 \%$ com a dose $2 \times$ N.C., na forma de calcário e gesso, indicando uma tendência do carreamento de bases atribuí- 
Tabela 1. Características químicas do solo, em duas profundidades, após a colheita do tomate, nos diferentes tratamentos. Petrolina, Embrapa Semi Árido, 2000

\begin{tabular}{|c|c|c|c|c|c|c|c|c|}
\hline \multirow{2}{*}{$\begin{array}{l}\text { N.C. }{ }^{1} \\
\text { (vezes) }\end{array}$} & Calcário & Gesso & \multirow{2}{*}{$\begin{array}{l}\text { Profundidade } \\
\text { (cm) }\end{array}$} & \multirow{2}{*}{$\begin{array}{c}\mathrm{PH} \\
\left(\mathrm{H}_{2} \mathrm{O}\right)\end{array}$} & $\mathrm{Ca}^{2}+$ & $\mathrm{Mg}^{2}+$ & $\mathrm{K}+$ & $\mathrm{Al}^{3}+$ \\
\hline & \multicolumn{2}{|c|}{ kg ha $^{-1}$} & & & \multicolumn{4}{|c|}{ cmolc dm $^{-3}$} \\
\hline \multirow[t]{2}{*}{0,0} & - & - & $0-20$ & 5,5 & 1,0 & 0,7 & 0,29 & 0,11 \\
\hline & & & $20-40$ & 5,3 & 1,0 & 0,9 & 0,27 & 0,16 \\
\hline \multirow[t]{2}{*}{0,5} & 1.000 & - & $0-20$ & 5,6 & 1,1 & 0,8 & 0,28 & 0,06 \\
\hline & & & $20-40$ & 5,3 & 1,0 & 0,9 & 0,24 & 0,09 \\
\hline \multirow[t]{2}{*}{1,0} & 2.000 & - & $0-20$ & 6,0 & 1,4 & 0,8 & 0,27 & 0,05 \\
\hline & & & $20-40$ & 5,6 & 1,2 & 0,9 & 0,24 & 0,06 \\
\hline \multirow[t]{2}{*}{2,0} & 4.000 & - & $0-20$ & 6,3 & 1,5 & 1,1 & 0,33 & 0,05 \\
\hline & & & $20-40$ & 6,1 & 1,4 & 0,9 & 0,26 & 0,05 \\
\hline \multirow[t]{2}{*}{0,5} & 667 & 333 & $0-20$ & 5,9 & 1,3 & 0,8 & 0,27 & 0,05 \\
\hline & & & $20-40$ & 5,5 & 1,1 & 0,8 & 0,22 & 0,13 \\
\hline \multirow[t]{2}{*}{1,0} & 1.334 & 666 & $0-20$ & 5,8 & 1,4 & 0,9 & 0,37 & 0,05 \\
\hline & & & $20-40$ & 5,3 & 1,3 & 0,9 & 0,30 & 0,11 \\
\hline \multirow[t]{2}{*}{2,0} & 2.667 & 1.333 & $0-20$ & 6,1 & 1,6 & 1,0 & 0,26 & 0,05 \\
\hline & & & $20-40$ & 6,0 & 1,5 & 1,0 & 0,25 & 0,05 \\
\hline
\end{tabular}

${ }^{1}$ Necessidade de calagem $\left(\mathrm{t} \mathrm{ha}^{-1}\right)$

do ao gesso (Alcarde, 1988; Quaggio et al., 1993).

Para o $\mathrm{K}^{+}$trocável, ocorreram alterações acima e abaixo dos valores relativos aos da testemunha nas duas profundidades, sendo que o maior incremento $(27,5 \%)$ foi obtido com a dose 1 x N.C., sob a forma de calcário e gesso, na camada superficial, e a maior redução $(18,5 \%)$ com a dose 0,5 x N.C., sob a forma de calcário e gesso, na camada subsuperficial. Provavelmente, essas alterações não interferiram no desenvolvimento das culturas devido às aplicações de potássio realizadas em sulco e através da água de irrigação por gotejo.

Em relação ao $\mathrm{Al}^{3+}$ trocável, foram obtidas reduções de 45,4 a 54,5\% na camada superficial com o emprego de calcário e calcário e gesso. Na camada subsuperficial, obteve-se reduções de 18,7 a $68,7 \%$, dependendo da dose e da forma do corretivo. Com as doses $0,5 \mathrm{e}$ $1 \times$ N.C. na forma Cal.Ges. os teores $\mathrm{Al}^{3+}$ ainda permaneceram em níveis que podem ser tóxicos (Tabela 1) para as culturas mais sensíveis, demonstrando que a associação do gesso ao calcário não foi tão eficiente para a neutralização do $\mathrm{Al}^{3+}$ quanto à forma única de calcário, que nessas doses reduziram o $\mathrm{Al}^{3+}$ para teores inferiores a $0,10 \mathrm{cmol} \mathrm{dm}^{-3}$. Com a dose mais alta, $2 \times$ N.C., as duas for- mas neutralizaram, praticamente todo alumínio tóxico.

É possível que, sendo o solo arenoso, o calcário tenha sido lixiviado pela precipitação pluviométrica de $566 \mathrm{~mm}$ que ocorreram no período de novembro/ $00 \mathrm{a}$ abril/01 e pelas irrigações efetuadas para o cultivo do tomateiro, neutralizando, também, o alumínio da camada mais profunda. Resultados semelhantes foram obtidos por Caires et al. (2001) num solo com $22 \%$ de argila, cultivado com soja.

A recuperação do cálcio do calcário pela análise química do solo foi de 19,4; 55,3 e $43,7 \%$ para as doses $1 \times$ N.C.; 2 x N.C. e 4 x N.C., sob a forma de calcário, respectivamente, nas duas profundidades. Isto sugere que uma quantidade razoável de $\mathrm{Ca}$, principalmente na dose 1 x N.C., foi absorvido pelo tomateiro e pelas ervas daninhas que lhe antecederam e/ou lixiviou além da profundidade $40 \mathrm{~cm}$, considerando tratar-se de um solo arenoso (92 e $82 \%$ de areia nas profundidades $0-20$ e $20-40 \mathrm{~cm}$, respectivamente). Na forma Cal.Ges., a lixiviação do cálcio deve ter sido ainda maior.

\section{Efeitos nos cultivos}

No que se refere às culturas, verificou-se efeitos significativos dos tratamentos sobre a incidência da podridão apical dos frutos do tomateiro
$\left(\mathrm{F}=5,85^{* *}\right)$ e a produtividade do melão $(\mathrm{F}=2,93 *)$. Não se constatou diferenças significativas entre as duas formas de corretivo na comparação por contraste sobre a ocorrência da podridão apical no tomate $\left(F=0,41^{\text {ns }}\right)$. Na análise de regressão da ocorrência da podridão apical como função das doses dos corretivos, não se encontrou modelo matemático que se ajustasse aos dados quando se fez análises isoladas pela forma Cal. ou Cal.Ges. Na análise conjunta das duas formas ajustou-se a equação seguinte: 0,94

$$
y=0,6702-0,5948 x+0,214 x^{2}, r^{2}=
$$

Derivando essa equação encontrouse a quantidade de corretivo, equivalente a 1,389 N.C., necessária para reduzir a ocorrência da podridão apical ao mínimo esperado, que é de $6,6 \%$, retornando ao valor original da transformação $\operatorname{arc} . \operatorname{sen} \sqrt{x}$. Com os dados observados, a menor ocorrência dessa desordem fisiológica foi de $6,0 \%$, obtida com aplicação de $2.000 \mathrm{~kg} \mathrm{ha}^{-1}$ de calcário (Tabela 2), equivalente a N.C., calculada pelo método indicado para a região (Cavalcanti et al., 1998). Em relação à testemunha, representa uma redução de $80 ; 4 \%$, superior à redução de $30 \%$ encontrada com o uso de 3,0 $\mathrm{t} \mathrm{ha}^{-1}$ de calcário para o tomate cv. Rossol nessa região por Pereira et al. (1979). 
Tabela 2. Produtividade e ocorrência da podridão apical nos frutos do tomate nos diferentes tratamentos. Petrolina, Embrapa Semi Árido, 2000

\begin{tabular}{|c|c|c|c|c|}
\hline \multirow{2}{*}{$\begin{array}{l}\text { N.C. }{ }^{1} \\
\text { (vezes) }\end{array}$} & Calcário & Gesso & \multirow{2}{*}{$\begin{array}{c}\text { Produção } \\
\left(\mathrm{t} \mathrm{ha}^{-1}\right)\end{array}$} & \multirow{2}{*}{$\begin{array}{c}\text { Podridão apical } \\
\%\end{array}$} \\
\hline & & & & \\
\hline 0,0 & - & - & 52,59 & $30,7 a$ \\
\hline 0,5 & 1.000 & - & 61,78 & $21,9 a b$ \\
\hline 1,0 & 2.000 & - & 60,95 & $6,0 \mathrm{c}$ \\
\hline 2,0 & 4.000 & - & 65,34 & $11,9 b c$ \\
\hline 0,5 & 667 & 333 & 65,37 & $14,4 b c$ \\
\hline 1,0 & 1.334 & 666 & 60,88 & $20,0 \mathrm{~b}$ \\
\hline 2,0 & 2.667 & 1.333 & 68,21 & $9,7 \mathrm{bc}$ \\
\hline Teste F & & & $0,4 \mathrm{~ns}$ & $5,8^{* *}$ \\
\hline C.V. (\%) & & & 21,2 & 22,9 \\
\hline
\end{tabular}

${ }^{1}$ Necessidade de calagem $\left(\mathrm{t} \mathrm{ha}^{-1}\right)$

${ }^{2}$ Valores seguidos pela mesma letra não diferem significativamente pelo teste Duncan a $5 \%$.

Tabela 3. Produtividade, peso médio de frutos (PMF) e sólidos solúveis totais (SST) de melão nos diferentes tratamentos. Petrolina, Embrapa Semi Árido, 2000

\begin{tabular}{|c|c|c|c|c|c|}
\hline \multirow{2}{*}{$\begin{array}{c}\text { N.C. }{ }^{1} \\
\text { (vezes) }\end{array}$} & Calcário & Gesso & \multirow{2}{*}{$\begin{array}{l}\text { Produção } \\
\left(\text { tha }^{-1}\right)\end{array}$} & \multirow{2}{*}{$\begin{array}{l}\text { SST } \\
(\%)\end{array}$} & \multirow{2}{*}{$\begin{array}{r}\text { PMF } \\
\text { (kg) }\end{array}$} \\
\hline & \multicolumn{2}{|c|}{$\left(\mathrm{kg} \mathrm{ha}^{-1}\right)$} & & & \\
\hline 0,0 & - & - & $16,77 \mathrm{c}$ & 11,5 & 1,370 \\
\hline 0,5 & 1.000 & - & $22,07 a b$ & 10,4 & 1,451 \\
\hline 1,0 & 2.000 & - & $24,52 a$ & 11,1 & 1,637 \\
\hline 2,0 & 4.000 & - & $22,52 a b$ & 11,0 & 1,514 \\
\hline 0,5 & 667 & 333 & $21,00 a b c$ & 10,3 & 1,468 \\
\hline 1,0 & 1.334 & 666 & $19,00 \mathrm{bc}$ & 10,0 & 1,554 \\
\hline 2,0 & 2.667 & 1.333 & $21,59 a b c$ & 10,8 & 1,593 \\
\hline Teste F & & & $2,9^{*}$ & $0,5 \mathrm{~ns}$ & $1,0 \mathrm{~ns}$ \\
\hline$\overline{C . V .}(\%)$ & & & 12,1 & 12,2 & 10,4 \\
\hline
\end{tabular}

${ }^{1}$ Necessidade de calagem $\left(\mathrm{t} \mathrm{ha}^{-1}\right)$

${ }^{2}$ Valores seguidos pela mesma letra não diferem significativamente pelo teste Duncan a $5 \%$.

Embora o teste F não tenha sido significativo para produtividade de tomate $\left(\mathrm{F}=0,44^{\mathrm{ns}}\right)$ devido, certamente, ao coeficiente de variação do experimento ter sido alto $(21,2 \%)$, os dados da Tabela 2 demonstram que os tratamentos com calcário e/ou calcário e gesso proporcionaram valores absolutos superiores ao da testemunha (15,7 a 29,7\%), sugerindo uma tendência forte de efeito positivo dos corretivos de cálcio sobre esse parâmetro da planta.

Em relação à cultura do melão, houve diferença significativa entre as duas formas de corretivo na produtividade, confirmada através do contraste $\left(\mathrm{F}=4,36^{*}\right)$. Observando os dados da Tabela 3 , constata-se que na forma Cal. as produtividades foram superiores às ob- tidas na forma Cal.Ges. Sob essa forma, o corretivo não exerceu efeito significativo na produtividade do melão, quando avaliado através da análise de regressão $\left(\mathrm{F}=0,73^{\mathrm{ns}}\right)$.

A superioridade da aplicação exclusiva do calcário pode ser atribuída a uma neutralização mais eficiente do $\mathrm{Al}^{3+}$ trocável em profundidade que a aplicação mista (Tabela 1). Constatou-se também, que houve uma maior relação dos teores de $\mathrm{Ca}^{2+} /\left(\mathrm{Mg}^{2+}+\mathrm{K}^{+}\right), 1,31$, do solo na camada de $0-20 \mathrm{~cm}$ de profundidade com aplicação única do calcário em comparação aos valores obtidos para aplicação conjunta de calcário e gesso, 1,10. Em solos ácidos e pobres em cálcio, recomenda-se que, além da calagem, sejam feitas adições deste nutriente nas adubações para os cultivos de olerícolas (Filgueira, 2000). Pereira et al. (2002) observaram que a adição de cálcio favoreceu um maior pegamento de frutos de melão, concorrendo para que houvesse um maior número de frutos por planta e, consequentemente, uma maior produtividade.

$\mathrm{Na}$ análise de regressão com os dados para o corretivo na forma Cal., obteve-se a equação: $r^{2}=0,99$.

$$
y=16821+6.3657-0,0012 x^{2}
$$

Por meio da derivada dessa equação, obteve-se a dose de $2.564 \mathrm{~kg} \mathrm{ha}^{-1}$ de calcário que proporcionaria uma produtividade máxima esperada de $24.980 \mathrm{~kg}$ $\mathrm{ha}^{-1}$ de melão. Essa dose foi superior à 
N.C. calculada pelo método indicado em Cavalcanti (1998). Entretanto, deve-se considerar que o cultivo do melão foi posterior ao cultivo do tomate na mesma área e iniciou-se onze meses depois da aplicação do calcário e por tratar-se de solo arenoso, uma quantidade razoável do corretivo já havia sido perdida, conforme demonstrou-se anteriormente.

Da mesma forma que aconteceu para a produtividade de tomate, todos tratamentos apresentaram valores absolutos de peso médio de frutos superiores, mas não significativos, ao da testemunha (Tabela 3). Provavelmente, a produtividade tenha dependido mais do número que do peso dos frutos. Para o teor de sólidos solúveis totais, também não se observou efeito significativo $\left(\mathrm{F}=0,60^{\mathrm{ns}}\right)$, cujos valores (Tabela 3 ) encontram-se em níveis iguais ou um pouco superiores ao valor mínimo exigido no mercado $(10,0 \%)$.

Nesse trabalho, pode-se concluir que a adição de calcário isolado ou com gesso proporcionou uma melhoria nas condições de $\mathrm{pH}, \mathrm{Ca}^{2+}, \mathrm{Mg}^{2+}$ e $\mathrm{Al}^{3+}$ do solo nas profundidades $0-20 \mathrm{~cm}$ e $20-40 \mathrm{~cm}$, com efeito mais pronunciado no aumento dos teores do $\mathrm{Ca}^{2+}$ e na redução do $\mathrm{Al}^{3+}$. O calcário isolado foi mais eficiente para neutralização do $\mathrm{Al}^{3+}$ em profundidade e para o cultivo do melão que o calcário associado ao gesso. Com 2,0 t ha $^{-1}$ de calcário, correspondendo a necessidade de calagem, foi suficiente para se obter um aumento de $46,2 \%$ na produtividade do melão e uma redução de $80,4 \%$ na ocorrência da podridão apical do tomate. Portanto, a gessagem não se mostrou necessária para essas culturas. Em solos argilosos e com maiores teores de $\mathrm{Al}^{3+}$, principalmente em profun- didade, a associação de calcário e gesso, ao contrário do observado no presente estudo, pode se mostrar mais eficiente.

\section{LITERATURA CITADA}

ALCARDE, J.C. Contraditória, confusa e polêmica: é a situação do gesso na agricultura. Informações Agronômicas, Piracicaba, n. 41, p. 1-3, 1988.

CAIRES, E.F.; FONSECA, A.F.; MENDES, J.; CHUEIRI, W.A.; MADRUGA, E.F. Produção de milho, trigo e soja em função das alterações das características químicas do solo pela aplicação de calcário e gesso na superfície em sistema de plantio direto. Revista Brasileira de Ciência do Solo, Campinas, v. 23, n. 2, p. 315-327, 1999.

CAIRES, E.F.; FONSECA, A.F.; FELDHAUS, I.C.; BLUM; J. Crescimento radicular e nutrição da soja cultivada no sistema plantio direto em resposta ao calcário e gesso na superfície. Revista Brasileira de Ciência do Solo, Campinas, v. 25, n. 4, p. 1029-1040, 2001.

CAVALCANTI, F.J.A., coord. Recomendações de adubação para o Estado de Pernambuco: $2^{\mathrm{a}}$ aproximação. Recife: IPA. 1998. 198 p.

EMBRAPA. Centro Nacional de Pesquisa de Solos (Rio de Janeiro,RJ). Manual de métodos de análises de solo. 2.ed. rev. atual. Rio de Janeiro, 1997. 212 p.:il. (EMBRAPA-CNPS. Documentos; 1).

FILGUEIRA, F.A.R. Novo manual de agrotecnologia moderna na produção e comercialização de hortaliças. Viçosa: UFV, 2000. $402 \mathrm{p}$.

FOLE, D.A.; GRIMM, S.S. Avaliação do efeito residual do fósforo por meio de métodos de extração e modelos matemáticos no Oxisol, Passo Fundo. Agronomia Sulriograndense, Porto Alegre, v. 9, n. 2, p. 205-221, 1973.

LESTER, G.E.; GRUSAK, M.A. Postharvest application of chelated and nonchelated calcium dip treatments to commercially grown honey dew melons: effects on peel attributes, tissue calcium concentration, quality, and consumer preference following storage. HortTechnology, v. 11, n. 4, p. 561-566, 1991

LIMA, J.A.; FERREIRA, P.E.; FONTES, R.R.; SOUZA, A.F. Relação cálcio e magnésio na produção comercial de tomate. Horticultura Brasileira, Brasília, v. 2, n. 2, p. 33-36, 1984.
MARTINS, O.C.; NOVAIS, R.F.; ALVAREZ V.V.H.; BARRO, N.F.; RIBEIRO, A.C. Resposta a aplicação de diferentes misturas de calcário e gesso em solos. II Crescimento de raízes, absorção de nutrientes e produtividade da soja. Revista Ceres, Viçosa, v. 45, n. 261, p. 451-466, 1998.

MAYFIELD, J.L.; SIMONNE, E.H.; MITCHELL, C.C.; SIBLEY, J.L.; EAKES, D.J.; BOOZER, R.T.; VINSON, E.L. Effect of liming materials on soil available nutrientes, yield, and grade distribution of double-cropped tomato and cucumber grown with plasticulture. Journal of Plant Nutrition, New York, v. 24, n. 1, p. 87-99, 2001.

PAIVA, E.A.S.; MARTINEZ, H.E.P.; CASALI, V.W.D.; PADILHA, L. Occurrence of blossomend rot in tomato as a function of calcium dose in the nutrient solution and air relative humidity. Journal of Plant Nutrition, New York, v. 21, n. 12, p. 2663-2670, 1998.

PEREIRA, A.J.; BLANK, A.E.; ALVARENG, M.A.R.; SOUZA, R.J. Aplicação de fontes e doses de cálcio na produção e qualidade de frutos de melão. Horticultura Brasileira, Brasília, v. 20, n. 3, p. 428-431, 2002.

PEREIRA, J.R.; FERNANDES, C.S.; CORDEIRO, G.G. Podridão estilar em tomate. Pesquisa Agropecuária Brasileira, Brasília, v. 14, n. 3, p. 237-241, 1979.

QUAGGIO, J.R.; RAIJ, B.; GALLO, P.B.; MASCARENHAS, H.A. Resposta da soja à aplicação de calcário e gesso e lixiviação de íons no perfil do solo. Pesquisa Agropecuária, Brasília, v. 28, n. 3, p. 375-383, 1993.

RAIJ, B. van. Gesso agrícola na melhoria do ambiente radicular no subsolo. São Paulo, Associação Nacional para Difusão de Adubos e Corretivos Agrícolas. 1988. 88 p.

RIBEIRO, A.C.; GUIMARÃES, P.T.G; ALVAREZ

V.V.H. Recomendação para o uso de corretivos e fertilizantes em Minas Gerais - $5^{\text {a }}$ aproximação. Viçosa, 1999. 359 p.

SAS Institute Inc., SAS/STAT User's guide, verson 8, Cary, NC: SAS Institute Inc., 1999. 3884 p.

SNEDECOR, G.W.; COCHRAN, W.G. Métodos estadísticos. México: Continental, 1971. 703 p.

SOUSA, D.M.G.; LOBATO, E.; REIN, T.A. Uso de gesso agricola nos solos dos Cerrados. Planaltina: EMBRAPA-CPAC, 1996. 20 p. (EMBRAPA-CPAC. Circular Técnica, 32)

SUMMER, M.E.; SHAHANDEH, H.; BOUTON, J.; HAMMEL, J. Amelioration of an acid soil profile through deep liming and surface application of gypsum. Soil Science Society America Journal, Madison, v. 50, n. 5, p. 1254 1278, 1986. 